\title{
Framing analysis como metodologia de estudlo para estratégias de legitimidade institucional: o caso JBS S.A. após escândalos de corrupção
}

\section{Framing analysis as methodology for institutional legitimacy strategies study: the JBS}

S.A. case after corruption scandals

Marcos Paulo da Silva ${ }^{a}$

ORCID: http://orcid.org/0000-0003-2868-4865

Maryanna Beserra de Almeida ${ }^{b}$

ORCID: https://orcid.org/0000-0001-8576-4103

Marcia Maria dos Santos Bortolocci Espejo ${ }^{c}$

ORCID: https://orcid.org/0000-0002-9081-781X

Elisabeth de Oliveira Vendramin ${ }^{d}$

ORCID: https://orcid.org/0000-0002-9082-2256

Robert Armando Espejo ${ }^{e}$

ORCID: https://orcid.org/0000-0002-0155-4465

Recebido em: 20/10/2020. Aprovado em: 23/02/2021

Resumo

O artigo volta-se ao universo da legitimidade social de organizações empresariais em tempos de crises a partir de um diálogo metodológico com a tradição da framing analysis. Busca-se identificar as estratégias de legitimação utilizadas pela empresa JBS S.A. nos anos de 2017 e 2018 em resposta aos danos à imagem causados por operações deflagradas pela Polícia Federal. São apresentados dados obtidos a partir do estudo de 37 comunicados aos investidores e de 62 notícias institucionais. Infere-se que as estratégias de ganho de legitimidade estão diretamente ligadas à função de enquadramento de atribuição de juízo moral ao passo em que as estratégias de recuperação de legitimidade vinculam-se à função de enquadramento da identificação de problemas.

Palavras-chave: Comunicação. Enquadramento. Legitimidade institucional. JBS S.A.
Abstract

The article focuses on the social legitimacy universe of business organizations in crisis scenarios based on a methodological dialogue with the framing analysis. It seeks to identify the legitimation strategies used by the company JBS S.A. in the years 2017 and 2018 in response to the damage to its image caused by Federal Police operations. The study considers 37 announcements to investors and 62 institutional news released. It can be inferred that JBS S.A's strategies for gaining institutional legitimacy are directly linked to the moral judgment attribution framing function, whereas legitimacy recovery strategies are linked to the problem identification function.

Keywords: Communication. Framing. Institutional legitimacy. JBS S.A.

\footnotetext{
${ }^{a}$ Universidade Federal de Mato Grosso do Sul (UFMS), Brasil. E-mail: silva_mp@uol.com.br

${ }^{\text {b }}$ Universidade Federal de Mato Grosso do Sul (UFMS), Brasil. E-mail: maryanna182@gmail.com

${ }^{c}$ Universidade Federal de Mato Grosso do Sul (UFMS), Brasil. E-mail: marciabortolocci@gmail.com

${ }^{d}$ Universidade Federal de Mato Grosso do Sul (UFMS), Brasil. E-mail: E-mail: elisabeth.vendramin@ufms.br

e Universidade Federal de Mato Grosso do Sul (UFMS), Brasil. E-mail: robert.espejo@ufms.br
} 


\section{Introdução}

Este estudo volta-se ao universo da legitimidade social de organizações empresariais a partir de um diálogo metodológico com a tradição da framing analysis (ENTMAN, 1991; 1993; GITLIN, 2003) - ou análise de enquadramento - como forma de averiguação de estratégias comunicacionais em cenários de crise. Como recorte empírico, a pesquisa se debruça sobre o caso da crise de legitimidade institucional vivenciada pelo grupo empresarial JBS S.A., a partir do envolvimento em graves esquemas de corrupção no Brasil, em especial entre 2017 e 2018. De um vértice metodológico, volta-se ao desvelamento das estratégias de legitimação institucional (SUCHMAN, 1995) em interface com o enquadramento retórico no terreno da comunicação corporativa. Nesse sentido, para além da contribuição oriunda da análise empírica propriamente dita, o artigo também aporta em uma contribuição teóricometodológica ao aproximar aportes de pesquisa oriundos de campos distintos: a Administração e a Comunicação.

No plano empírico, busca-se identificar as estratégias retóricas de legitimação utilizadas pela empresa JBS S.A. em resposta ao dano à sua imagem causado pelas Operações Carne Fraca e Bullish deflagradas pela Polícia Federal e pelo envolvimento do ex-presidente da empresa, Joesley Batista, em escândalos de corrupção. A escolha da JBS S.A como objeto de pesquisa sustenta-se no impacto das ações do grupo no mercado brasileiro, além de tratar-se de um caso peculiar de trajetória de empresa brasileira que em poucas décadas deixa o escopo de uma microempresa para tornar-se referência mundial em seu ramo de atuação. Não por acaso, a imagem da JBS S.A. afeta diretamente o mercado de trabalho, de ações e a reputação do Brasil externamente.

Nesse sentido, a pesquisa contribui para identificar a forma como se dá a comunicação entre a instituição e a sociedade a partir dos comunicados aos investidores e das notícias institucionais divulgadas pela empresa nos anos de 2017 e 2018, ou seja, após o agravamento da crise de legitimidade institucional com a publicização dos casos de corrupção. O percurso metodológico do artigo remete a uma proposta de articulação das funções de enquadramento definidas por Entman $(1991$; 1993) às modalidades de legitimidade institucional apresentadas por Suchman (1995). 


\title{
A framing analysis
}

A primeira referência ao termo "frame" como método na pesquisa social é atribuída ao sociólogo Erving Goffman, na década de 1970, a partir do desenvolvimento de uma proposta de análise psicossocial denominada "framing analysis" - ou análise dos quadros da experiência social. Nas palavras de Goffman (2012, p. 30):

\begin{abstract}
Quando os indivíduos se interessam por qualquer situação usual, eles se confrontam com a pergunta: 'O que está acontecendo aqui?'. Quer formulada explicitamente, como em momentos de confusão ou dúvida, ou tacitamente, em ocasião de certeza habitual, a pergunta é feita e a resposta a ela é presumida na maneira como os indivíduos passam então a tocar os assuntos que têm diante de si.
\end{abstract}

Para o sociológico, quadros (frames) de referência são acionados como um conjunto de princípios que coordenam a interpretação subjetiva dos eventos e fatos. Tais enquadramentos instauram-se no processo da construção de significados direcionando a forma como a realidade é decodificada e interpretada intersubjetivamente. Os quadros de referência constituem, nesse sentido, estruturas de símbolos que confluem na atribuição de significados ancorados em um contexto cultural e em uma determinada situação.

A proposta seminal de Goffman (2012) é incorporada no terreno dos estudos de mídia a partir de pesquisas sobre os enquadramentos técnicos empregados nas coberturas noticiosas. Robert Entman $(1991 ; 1993)$ destaca-se nesse cenário ao sistematizar uma série de funções de enquadramento presentes nos conteúdos jornalísticos. O autor aporta na concepção de enquadramento ao desenvolver uma análise comparativa da cobertura noticiosa nos Estados Unidos de dois acidentes aéreos ocorridos em circunstâncias semelhantes na década de 1980: um avião coreano da Korean Air Lines, em 1983, e um avião iraniano da Iran Air, em 1988. Em suma, de acordo com o estudo de Entman (1991), as notícias construíram um enquadramento de que o avião coreano havia sido vítima de um atentado, consequência de um ataque perpetrado pelos soviéticos, ao passo em que a causa da tragédia com o avião iraniano seria um acidente motivado por um problema técnico. Nesse ínterim, o estudo demonstrou como o enquadramento jornalístico foi responsável por definir interpretações bastante diferentes para ocorrências similares.

Umas das principais conclusões dos estudos de Entman $(1991$; 1993) remete à natureza do processo de enquadramento que, tal como a metáfora fotográfica, não apenas destaca determinadas características de um fato como obscurece ou omite outras. Ademais, os enquadramentos acontecem em pelo menos quatro locais no processo de 
comunicação: no comunicador, no texto, no receptor e na cultura. Entman (1993), finalmente, define quatro funções ocorridas nas dinâmicas de enquadramento jornalístico: 1) a definição de um problema; 2) o diagnóstico de causas; 3) o julgamento moral; 4) e a atribuição de recomendações.

Voltado ao estudo dos movimentos sociais norte-americanos dos anos 1960, o também sociólogo Todd Gitlin (2003), por seu turno, vincula de forma mais direta a framing analysis aos aspectos ideológicos disseminados na sociedade, ajudando a popularizar o método analítico. Na perspectiva do autor, “enquadramentos de mídia são padrões persistentes de cognição, interpretação e apresentação, de seleção e exclusão, pelo qual manipuladores de símbolos rotineiramente organizam o discurso, seja verbal ou visual” (GITLIN, 2003, p. 7, tradução nossa). Para valer-se da metáfora trabalhada por Gitlin (2003), os enquadramentos jornalísticos representam espécies de "holofotes" que projetam luz sobre determinadas ocorrências sociais, obscurecendo as demais.

Mostra-se significativo, nesse contexto, que os primeiros estudos de enquadramento, inclusive em razão do momento histórico em que emergem, são mobilizados originalmente para desvelar e desconstruir os sentidos implícitos por trás de conteúdos noticiosos no escopo dos paradigmas da objetividade e da imparcialidade jornalística (ENTMAN, 1991; 1993; GITLIN, 2003). Nesse cenário, a aplicação da framing analysis no âmbito da comunicação institucional (ou seja, numa lógica eminentemente mercadológica), como proposta neste trabalho, pode parecer destituída de sentido. Entretanto, em uma perspectiva ampliada, como a apresentada pelo também pesquisador norte-americano Jim Juypers (2009), tal relação preenche-se de pertinência. Kuypers (2009) oferece uma contribuição significativa ao debate ao relacionar os enquadramentos jornalísticos ao universo das estratégias retóricas. $\mathrm{O}$ autor assevera que a análise de enquadramento constitui "uma maneira particularmente útil para compreender o impacto da retórica", podendo ser mobilizada para entender melhor qualquer artefato argumentativo, em especial no terreno comunicacional:

\footnotetext{
Enquadrar envolve como a imprensa organiza o contexto através do qual o público encara suas notícias. Na sua essência, este é um processo retórico, e é por isso que acredito que a teoria de enquadramento pode ser especialmente frutífera quando adaptada para uma perspectiva retórica (KUYPERS, 2009, p. 185 , tradução nossa).
}

Nesse horizonte, o aparato da framing analysis reveste-se de validade como recurso metodológico para o estudo das estratégias comunicacionais imbricadas nas 
políticas de legitimação de organizações, em especial em momentos agudos de crise, a exemplo do caso da JBS S.A., ao qual este estudo se debruça.

\section{O processo de legitimação institucional}

Uma empresa pode ser definida como uma estrutura organizacional constituída com a finalidade específica de integrar o mercado. Trata-se, portanto, de uma pessoa jurídica formada por empresários e/ou sócios com o objetivo de oferecer um produto ou serviço, podendo ou não visar lucro no interior de seu contexto de ação (FERNANDES, ZANELLI, 2006). No escopo dessas características, via de regra, a organização costuma elaborar um conjunto de ações para consolidar sua imagem, seu desempenho e sua sustentabilidade frente aos stakeholders, que podem ser acionistas, clientes, fornecedores, investidores, empregados ou o próprio governo, bem como órgãos reguladores. Para uma empresa consolidar sua imagem perante tais públicos, uma das principais estratégias é a construção de relacionamentos que possam estreitar laços e alimentar sua fidelização em razão, dentre outros fatores, da comunicação direta e constante (MAFEI, CECATO, 2011).

Nesse ínterim, o processo de legitimação institucional caracteriza-se por uma busca das organizações pela aprovação da sociedade. Essa aprovação é necessária para que o público invista recursos e permite a própria continuidade das empresas. Para adquirir e administrar a legitimidade, as organizações criam argumentos, imagens e "personalidades" com o objetivo de desenvolver uma identificação e de se aproximar de seus stakeholders (LINDBLOOM, 1994). Tal processo tem como pressupostos as concepções de verdade e de conhecimento, criando uma representação da realidade empregada de forma consciente com o objetivo de persuasão. Considerando que a legitimidade não é estática, as organizações precisam saber como gerenciá-la, utilizando estratégias específicas (SUCHMAN, 1995).

O conceito de legitimidade, inicialmente utilizado na Ciência Política, sofreu mudanças para se adaptar ao universo corporativo. Para Beuren, Gubiani e Soares (2009), a legitimidade corporativa insere a instituição em um contexto social no qual suas ações estão baseadas em um contrato relacionado entre a responsabilidade social e a política. Buscando a legitimação perante a sociedade, as empresas direcionam suas ações visando o alcance de reconhecimento nos campos relativos à sustentabilidade, à conscientização 
ambiental, à cidadania, à cultura, aos costumes e ao sistema normativo jurídico (CONCEIÇÃO et al., 2011).

Para Suchman (1995), a legitimidade pode ser caracterizada pela percepção geral da sociedade de que as ações, serviços e produtos fornecidos por uma organização são desejáveis ou apropriadas dentro do sistema de valores, de crenças e de normas vigentes. Essa percepção remete a uma visão coletiva, permitindo que a organização tenha aprovação pública ainda que distante de valores individuais, desde que atenda às crenças e aos valores socialmente aceitos. A legitimidade também é uma das responsáveis por projetar uma imagem de estabilidade e de confiabilidade à organização e não afeta apenas o modo como a empresa é vista pelo seu público-direto (consumidores), mas também como é compreendida pelas mais diversas instâncias da sociedade (SUCHMAN, 1995). Uma empresa considerada legítima pelo público é vista como significativa, importante e confiável. Tais características são essenciais para que existam investimentos de usuários externos, tornando a legitimidade uma tática e um fator de competitividade, pois permite a capacidade de angariar recursos necessários à sobrevivência e à lucratividade (DIAS FILHO, 2007). Por outro lado, uma organização "ilegítima" torna-se vulnerável e pode ser percebida como negligente, irracional e desnecessária.

Suchman (1995) defende que os resultados dependem de qual tipo de legitimação a organização procura, sistematizando três modalidades: 1) a legitimidade pragmática; 2) a legitimidade moral; e 3) a legitimidade cognitiva. Todos os tipos envolvem uma percepção generalizada de que a organização é apropriada, aceita e desejada pelos sistemas de crenças e normas vigentes. Pettigrew (1977) lembra que a legitimidade se trata de um recurso difuso e dinâmico, mas que sua importância, uma vez alcançada e administrada, é capaz de gerar resultados de grande relevância.

De acordo com Suchman (1995), a legitimidade pragmática apoia-se no interesse próprio da organização em atender seu público mais imediato. Em geral, é sustentada por meio de trocas diretas entre a organização e seu público, porém, pode envolver também ações para ampliar a política, a economia ou atos sociais que afetam o desenvolvimento institucional com o objetivo de alcançar o bem-estar generalizado. Em linhas gerais, a legitimidade pragmática trata de uma espécie de troca, o apoio a uma política organizacional baseada no valor esperado dessa ação para um conjunto particular, podendo ser conhecida também como legitimidade de influência. Devido à grande personalização de serviços, as organizações são vistas como indivíduos personificados que possuem objetivos, gostos, estilos e personalidades. Com base nessa percepção, o 
público atribui legitimidade às organizações que detêm valores, estilos e personalidades semelhantes às suas. Esse tipo de identificação pode se tornar essencial para avaliações positivas generalizadas, além da possibilidade de atenuar eventuais falhas e erros em virtude da crença difundida em torno do suposto caráter da organização (SUCHMAN, 1995).

A legitimidade moral, por sua vez, reflete uma avaliação normativa positiva da organização e de suas atividades, ou seja, baseia-se em julgamentos morais sobre uma determinada atividade, se é desenvolvida de maneira correta e se reflete a moral vigente. O objetivo é que as atividades da organização promovam o bem-estar social e ambiental, conforme as normas vigentes no universo no qual está inserida. Porém, isso não faz com que a organização seja livre de interesses; pelo contrário, muitas vezes vale-se de gestos simbólicos para manipular a percepção do público por meio de discursos que reforçam alegações morais de interesse próprio (SUCHMAN, 1995). Segundo Suchman (1995), na legitimidade moral as propriedades técnicas dos produtos são definidas socialmente e não existem de forma concreta. Assim, a organização, além de produzir imagens socialmente valorizadas, também pode adotar técnicas e procedimentos socialmente aceitos. Essa medida é mais eficaz quando existe a evidenciação, por parte da organização, que demonstra seu esforço para alcançar fins valorizados socialmente ainda que estes não sejam visíveis.

Finalmente, a legitimidade cognitiva é composta por duas vertentes distintas: a legitimidade baseada na compreensão e a legitimidade garantida. Suchman (1995), defende que na legitimidade baseada na compreensão a organização esforça-se para convencer a sociedade de que seus produtos são necessários e atendem a um propósito. Para buscar essa legitimidade, a organização deve alcançar tanto o sistema de crenças sociais vigentes quanto a realidade experimentada pelo público no dia a dia. De acordo com o autor, a legitimidade "garantida" retrata um cenário em que a utilização de técnicas específicas é suficiente para administrar possíveis falhas, transformando-as em um conjunto de dados inter-relacionados. O propósito é que o público julgue os procedimentos utilizados como a melhor forma de exercício das atividades ou que levem ao melhor produto (SUCHMAN, 1995).

As estratégias apontadas por Suchman (1995) relacionadas às modalidades de legitimidade pragmática, moral e cognitiva distribuem-se em ações de ganho, manutenção e recuperação, como explicitado no Quadro 1: 
Marcos Paulo da Silva, Maryanna Beserra de Almeida, Marcia Maria dos Santos Bortolocci Espejo, lisabeth de Oliveira Vendramin \& Robert Armando Espejo

Quadro 1 - Resumo das estratégias de legitimação de Suchman (1995)

\begin{tabular}{|c|c|c|c|}
\hline & GANHAR & MANTER & RECUPERAR \\
\hline Pragmática & $\begin{array}{ll}\text { Conforme as exigências: } \\
\checkmark & \text { Responder } \\
& \text { necessidades } \\
\checkmark & \text { Cooptar base de apoio } \\
\checkmark & \text { Construir reputação } \\
& \\
\text { Selecionar mercados: } \\
\checkmark \quad \text { Localizar públicos } \\
\quad \text { amigáveis } \\
\checkmark \quad \text { Recrutar base de apoio } \\
\quad \text { amigável } \\
\text { Anunciar: } \\
\checkmark \quad \text { Anunciar o produto } \\
\checkmark \quad \text { Anunciar a imagem }\end{array}$ & $\begin{aligned} & \text { Monitorar preferência: } \\
& \checkmark \text { Consultar opinião de } \\
& \text { líderes de grupos de } \\
& \text { interesse } \\
& \\
& \text { Proteger realizações: } \checkmark \\
& \checkmark \text { Política de } \\
& \text { confiabilidade } \\
& \checkmark \text { Comunicar } \\
& \text { honestamente } \\
& \checkmark \text { Estoque de boa } \\
& \text { vontade }\end{aligned}$ & $\begin{array}{l}\text { Negar } \\
\text { Criar monitoramento }\end{array}$ \\
\hline Moral & $\begin{aligned} & \text { Adaptar-se aos ideais: } \\
& \checkmark \text { Produzir resultados } \\
& \text { adequados } \\
& \checkmark \text { Vincular-se a } \\
& \text { instituições } \\
& \text { consideradas legítimas } \\
& \checkmark \text { Oferecer } \\
& \text { demonstrações } \\
& \text { simbólicas } \\
& \text { Selecionar domínio: } \\
& \checkmark \text { Definir metas } \\
& \\
& \text { Persuadir: } \\
& \checkmark \text { Demonstrar sucesso } \\
& \checkmark \text { Trazer adeptos }\end{aligned}$ & 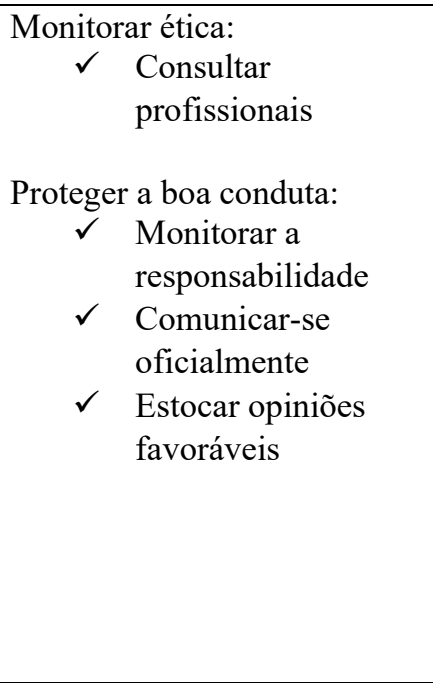 & $\begin{array}{ll}\text { Desculpar/Justificar } \\
\begin{aligned} & \text { Desassociar: } \\
& \checkmark \text { Substituir } \\
& \text { pessoal } \\
& \checkmark \text { Rever práticas } \\
& \checkmark \text { Reconfigurar }\end{aligned}\end{array}$ \\
\hline Cognitiva & $\begin{aligned} & \text { Adaptar-se aos modelos: } \\
& \checkmark \text { Reproduzir normas } \\
& \checkmark \text { Formalizar operações } \\
& \checkmark \text { Profissionalizar } \\
& \text { operações } \\
& \\
& \text { Selecionar rótulos: } \\
& \checkmark \text { Procurar certificação } \\
& \\
& \text { Institucionalizar: } \\
& \checkmark \text { Persistir } \\
& \checkmark \text { Popularizar novos } \\
& \text { modelos } \\
& \checkmark \text { Padronizar novos } \\
& \text { modelos }\end{aligned}$ & $\begin{aligned} & \text { Monitorar perspectivas: } \\
& \checkmark \text { Consultar quem tem } \\
& \text { dúvida } \\
& \\
& \text { Proteger hipóteses: } \\
& \checkmark \text { Simplificar } \\
& \checkmark \text { Falar pontualmente } \\
& \checkmark \text { estocar } \\
& \text { vínculos/conexões }\end{aligned}$ & Explicar \\
\hline
\end{tabular}

Fonte: Adaptado Lamberti e Lettieri (2011)

Entende-se, nesse cenário, que a legitimidade de uma organização pode ser questionada por diversos fatores: diferentes expectativas sociais, mudança de comportamento ou crença, ou algum evento ocorrido que tenha impacto sobre a imagem 
da empresa, como um desastre, um problema ambiental relacionado às suas ações ou um caso de corrupção. O exemplo da JBS S.A reveste-se, assim, de pertinência significativa para aplicação da análise.

\section{O caso JBS S.A. e os enquadramentos da crise}

A JBS S.A. é uma das maiores empresas alimentícias do mundo, reconhecida internacionalmente como a maior empresa de processamento de proteína animal, com faturamento global em 2015 de R\$ 163 bilhões (J\&F, 2017). A empresa brasileira foi fundada no ano de 1953, na cidade de Anápolis, Goiás, quando José Batista Sobrinho iniciou uma pequena planta de abate chamada "Casa de Carnes Mineira", com capacidade para 5 cabeças de gado por dia. Entre 1970 e 2001, a JBS S.A. passou por uma expansão contínua, alcançando a capacidade diária de abate de 5,8 mil cabeças (JBS, 2017).

Apesar da aceitação mercadológica e da reputação da empresa (JBS, 2015), em 17 março de 2017 a organização foi envolvida na operação Carne Fraca, deflagrada pela Polícia Federal com o objetivo de desarticular uma organização criminosa que envolvia fiscais agropecuários federais e empresários do agronegócio que praticavam crimes de corrupção. As investigações tiveram início em 2015 e ocorreram em seis estados e no Distrito Federal, abarcando mais de 1,1 mil agentes federais que cumpriram 309 mandados judiciais, sendo 194 de busca e apreensão. Além de corrupção ativa, as empresas envolvidas foram indiciadas pela adulteração de produtos por meio da utilização de ácido sórbico em carnes congeladas e em carnes in natura; prolongamento da expiração da validade dos produtos; injeção de água na carne de frango; substituição de carne de peru por soja; linguiças e salsichas recheadas fora do padrão estipulado pelo Ministério da Agricultura, Pecuária e Abastecimento (MAPA) e mais irregularidades nos produtos e nos procedimentos (POLÍCIA FEDERAL, 2017).

O impacto foi imediato: a exportação diária que era, em média, de 63 milhões de dólares caiu para 74 mil dólares em apenas quatro dias após a divulgação da operação. As ações da JBS S.A. na bolsa de valores B3 também caíram 10,59\% um dia após a divulgação da operação Carne Fraca. O total da perda de ações da empresa, até maio de 2017, dois meses após os escândalos, foi de 15,35\%. No pregão de maio de 2017, o valor de mercado da empresa era de 27,6 bilhões de dólares; antes do escândalo, a estimativa do valor total da empresa era de 32,6 bilhões de dólares (G1, 2017). Dois meses após o escândalo da operação Carne Fraca, a JBS S.A. novamente foi alvo de investigação pela 
Marcos Paulo da Silva, Maryanna Beserra de Almeida, Marcia Maria dos Santos Bortolocci Espejo, lisabeth de Oliveira Vendramin \& Robert Armando Espejo

Polícia Federal, que deflagrou, em 12 de maio de 2017, a operação Bullish, para apurar fraudes e irregularidades em aportes concedidos pelo Banco Nacional de Desenvolvimento Econômico e Social (BNDES). O ex-presidente da JBS S.A., Joesley Batista, também teve seu nome envolvido em outras operações da Polícia Federal, dentre elas as operações Greenfield, Cui Bono? e Lava Jato. O envolvimento da JBS S.A. em escândalos de corrupção comprometeu a imagem da empresa, levando à perda de valor e de confiança dos mercados interno e externo.

Nesse contexto, os dados da presente pesquisa foram coletados com base nos comunicados da empresa aos investidores, divulgados por meio do site www.jbss.infoinvest.com.br entre os anos 2017 e 2018; e nas notícias institucionais veiculadas no site oficial (www.jbs.com.br) da empresa no mesmo período. Para a análise dos dados, foram elaboradas fichas individuais para cada documento. Assim, cada ficha passou a conter: a) o tipo de documento; b) o canal em que foi disponibilizado; c) a data; d) o texto original; e d) os fragmentos que permitiram a análise do enquadramento e da estratégia de legitimação subsequente. Ao todo, foram estudadas 99 fichas, das quais 37 são de comunicados aos investidores e 62 referentes às notícias divulgadas pela empresa. O formato e o propósito de cada modalidade de documento são diferentes; dessa forma, foram identificados enquadramentos e estratégias retóricas de legitimação distintas com o objetivo de levar a mobilizações específicas no público.

Em relação aos comunicados enviados aos investidores, a análise a partir das funções de enquadramento definidas por Entman (1991; 1993) mostra que o foco da empresa tratou de definir um problema específico, buscando isolar o dano à imagem a um aspecto único que pode ser recuperado/restaurado uma vez tomadas as medidas necessárias. Dos 40 enquadramentos usados nos comunicados aos investidores, o mais recorrente (28) foi a definição de um problema específico, quadro de referência definido por determinar e isolar a situação problema, distanciando-a da imagem da empresa. Os demais foram distribuídos em números menores (8 não tiveram nenhum enquadramento, 2 fazem julgamentos morais e 2 sugerem uma solução), tal como expresso na Figura 1: 
Figura 1 - Funções de enquadramento utilizadas nos comunicados da JBS S.A. aos investidores no período de 2017 e 2018

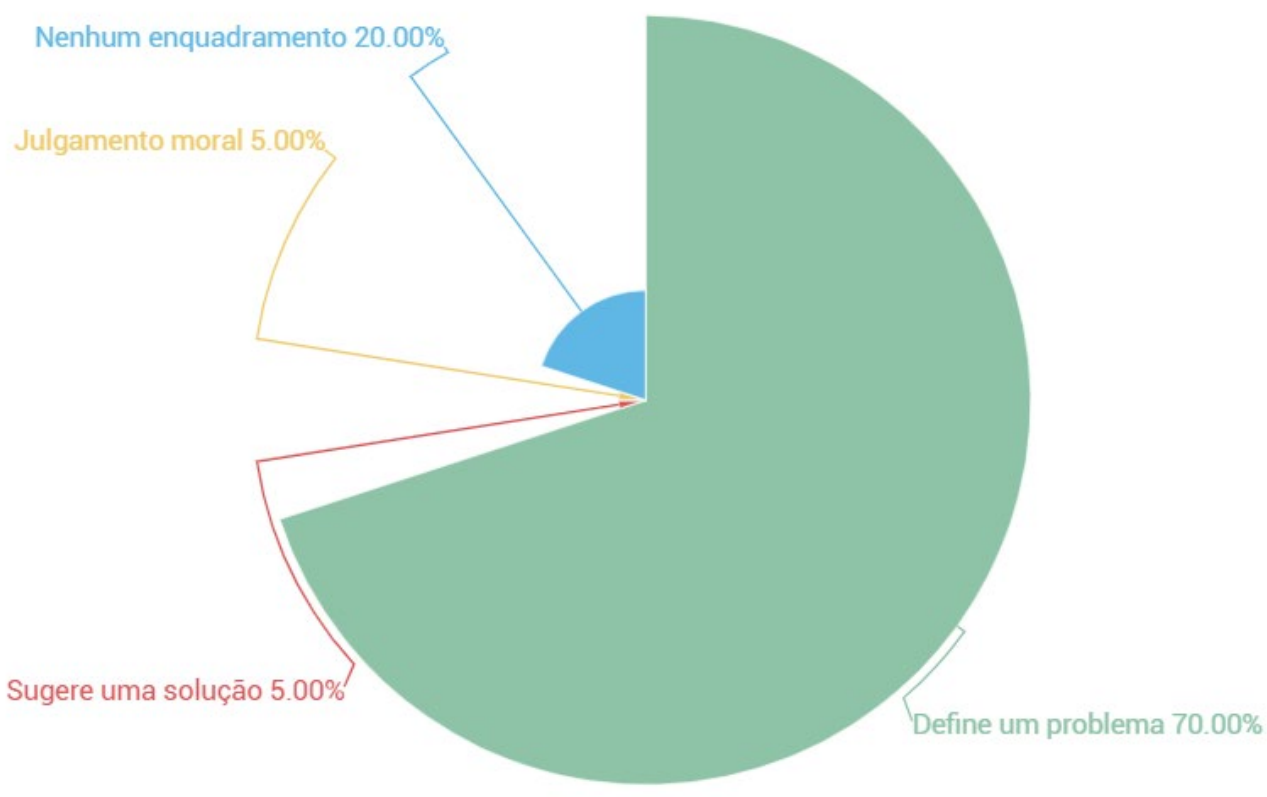

Fonte: Elaborado pelos autores para a finalidade do estudo

Denota-se dessa estratégia que o foco da empresa JBS S.A. ao se comunicar com seus investidores foi evidenciar que a companhia é uma empresa de sucesso, próspera no mercado nacional e internacional, que enfrentou um problema específico - um caso de corrução -, mas que se propôs a resolvê-lo por meio de reestruturações e substituição de pessoal. As palavras mais utilizadas nos comunicados aos investidores, presentes na Figura 2, são: JBS (255), companhia (222), mercado (139), informação (94) e empresa (86).

Figura 2 - Nuvem de palavras extraída dos comunicados da JBS S.A. aos investidores no período de 2017 e 2018

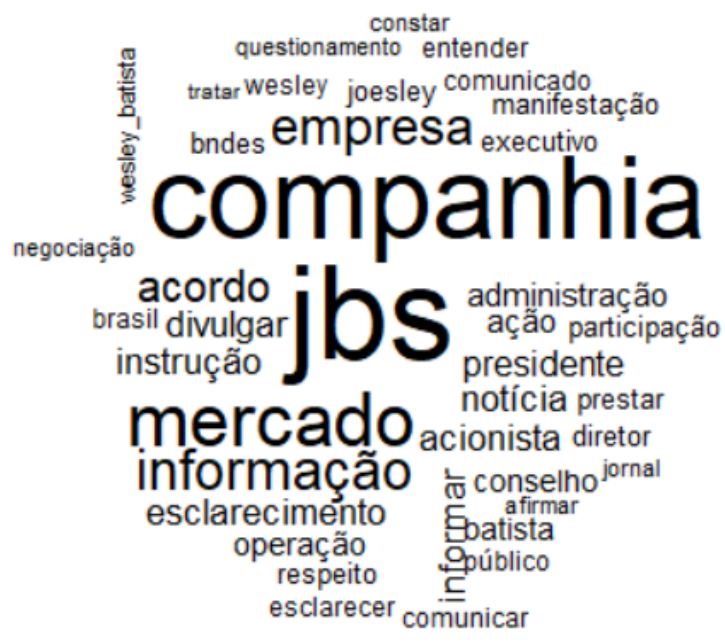

Fonte: Elaborado pelos autores para a finalidade do estudo 
Nota-se que tanto os substantivos quanto os verbos utilizados pela empresa estão ligados ao sentido de informar, esclarecer, comunicar e divulgar informações sobre os escândalos, explicitando o contexto e procurando justificar e retificar a conduta desabonadora perante o público-alvo. Tal recurso de enquadramento mobiliza majoritariamente uma estratégia, na acepção de Suchman (1995), devotada à recuperação da legitimidade.

Figura 3 - Estratégias de legitimação identificadas nos comunicados da empresa aos investidores no período de 2017 e 2018

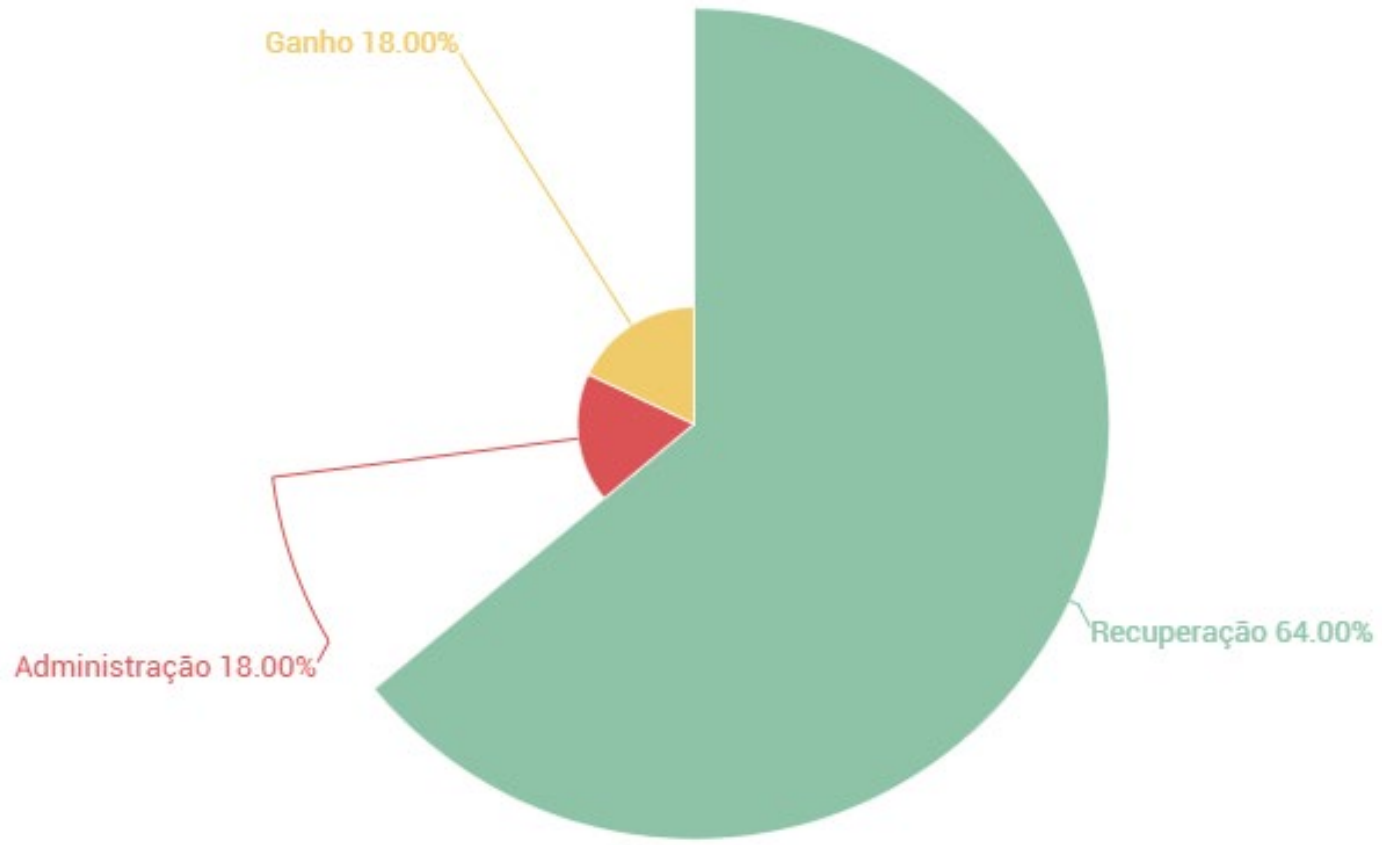

Fonte: Elaborado pelos autores para a finalidade do estudo

A Figura 3 ilustra que a estratégia de legitimidade mais utilizada pela JBS S.A. em associação a um enquadramento argumentativo de "identificação de um problema" no período em questão é a de recuperação, totalizando 39 ocorrências. Já, as estratégias de ganho e de administração da legitimidade apareceram 11 vezes cada. Do ponto de vista retórico, ao lançar mão de um enquadramento argumentativo de identificação e posterior isolamento de um problema socialmente conhecido (um vultuoso caso de corrução que levou a empresa e seus gestores ao foco de ao menos quatro operações da Polícia Federal), a política de comunicação disponibilizada aos investidores da JBS S.A. mobiliza as ações de "desculpar/justificar" no plano da legitimidade pragmática, passando no âmbito da legitimidade moral pelo expediente da dissociação da marca ao escândalo a partir da substituição de pessoal (no caso, os próprios gestores envolvidos nos esquemas) e pela 
revisão de práticas. Finalmente, no plano da legitimidade cognitiva, a empresa recorre ao estratagema da racionalidade por meio da disseminação de um sentido explicativo ao fenômeno, o que se diferencia de um projeto retórico de cunho subjetivo voltado à persuasão por meio de aspectos emotivos.

$\mathrm{O}$ estudo dos enquadramentos acionados pela empresa no âmbito das notícias institucionais divulgadas em seu site, todavia, revela uma estratégia argumentativa distinta. No conjunto das notícias divulgadas no período de 2017 e 2018, foram identificadas 104 estratégias de legitimação e 60 enquadramentos argumentativos. No que tange aos enquadramentos, conforme elucida a Figura 4, a atribuição de julgamento moral foi a função de enquadramento mais utilizada para destacar as informações relevantes para a empresa, presente em 44 notícias distintas, seguida pela sugestão de soluções (4) e pela definição de um problema específico, que foi identificada apenas uma vez nas notícias do período analisado. Cabe destacar que a definição de um problema foi o mais utilizado nos comunicados aos investidores. Em 12 notícias, não foi possível identificar funções de enquadramento explícitas.

Figura 4 - Funções de enquadramento utilizadas nas notícias institucionais veiculadas pela JBS S.A. no período de 2017 e 2018

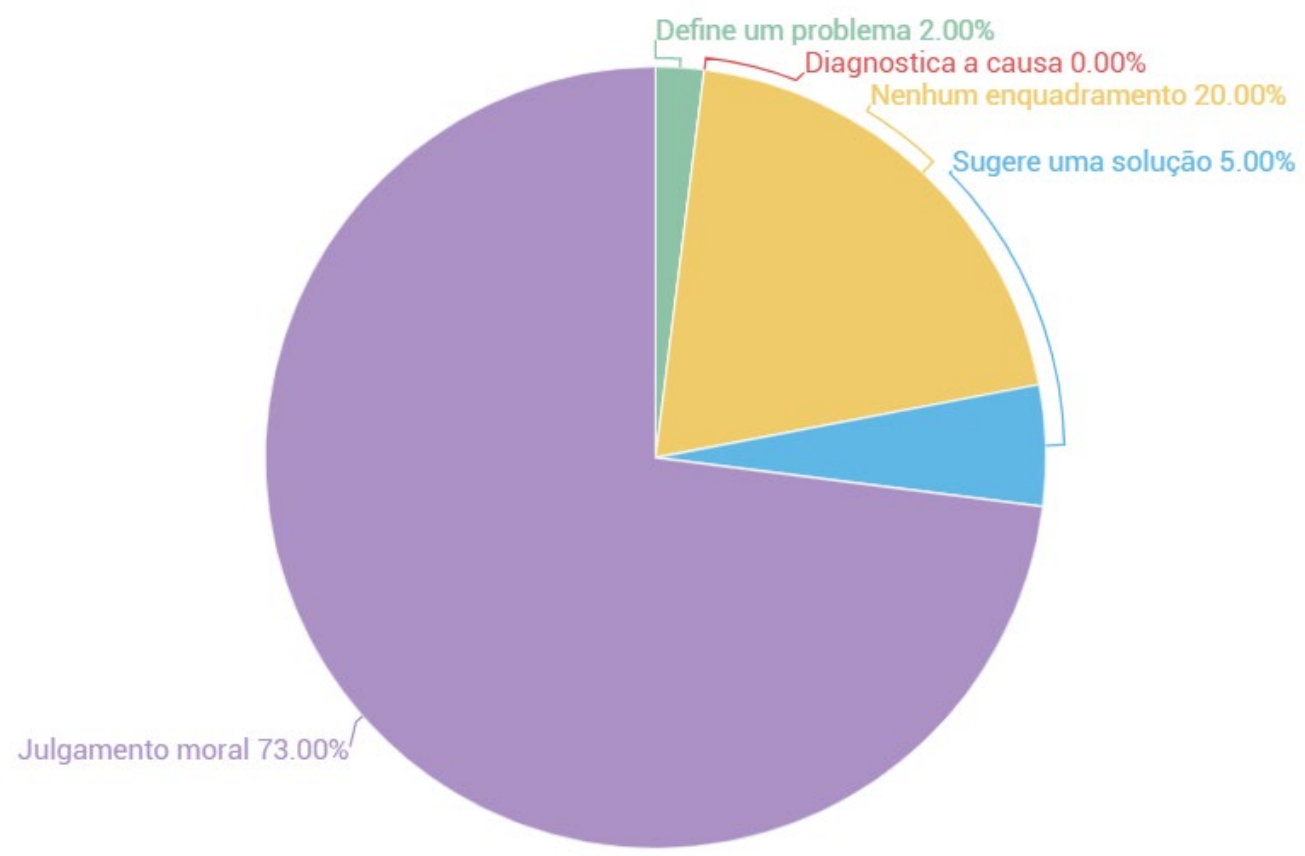

Fonte: Elaborado pelos autores para a finalidade do estudo

$\mathrm{Na}$ prática, o enquadramento argumentativo projetou luz na evidenciação do sucesso institucional, nos investimentos em ações voltadas à sustentabilidade, ao bem- 
estar animal e a ações sociais, bem como no reconhecimento da empresa por meio de prêmios e certificações. As palavras mais utilizadas nas notícias institucionais, ilustradas na Figura 5, vinculam-se à necessidade de explicitar ao consumidor a qualidade e a segurança dos produtos, além de ações destinadas ao bem-estar animal, à sustentabilidade e a ações ambientais. Uma vez mais, são utilizados mais substantivos e adjetivos do que verbos.

Figura 5 - Nuvem de palavras extraída das notícias institucionais veiculadas pela JBS S.A. no período de 2017 e 2018

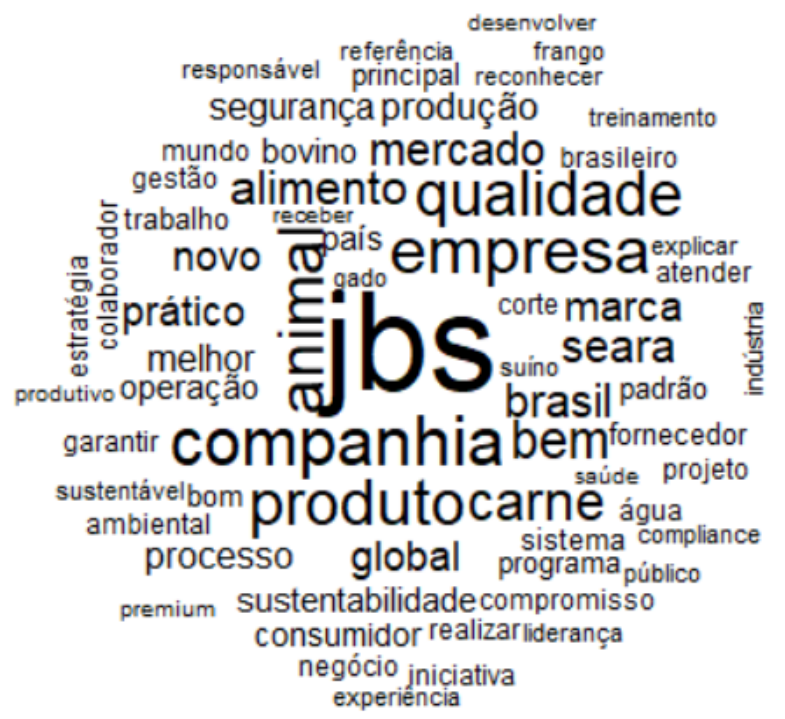

Fonte: Elaborado pelos autores para a finalidade do estudo

A análise denota que os enquadramentos argumentativos acionados pela JBS S.A. em suas notícias institucionais levam a estratégias de legitimidade distintas do posicionamento adotado no caso dos comunicados aos investidores. Diferentemente daquele âmbito, o recurso de legitimação mais utilizado nas notícias da empresa consiste na estratégia de ganho, totalizando 74 ocorrências. Conforme demonstra a Figura 6, a estratégia de administração de legitimidade foi identificada 18 vezes e, a menos utilizada, com apenas 12 ocorrências, foi a de recuperação de legitimidade. 
Figura 6 - Estratégias de legitimação utilizadas nas notícias institucionais veiculadas pela empresa no período de 2017 e 2018

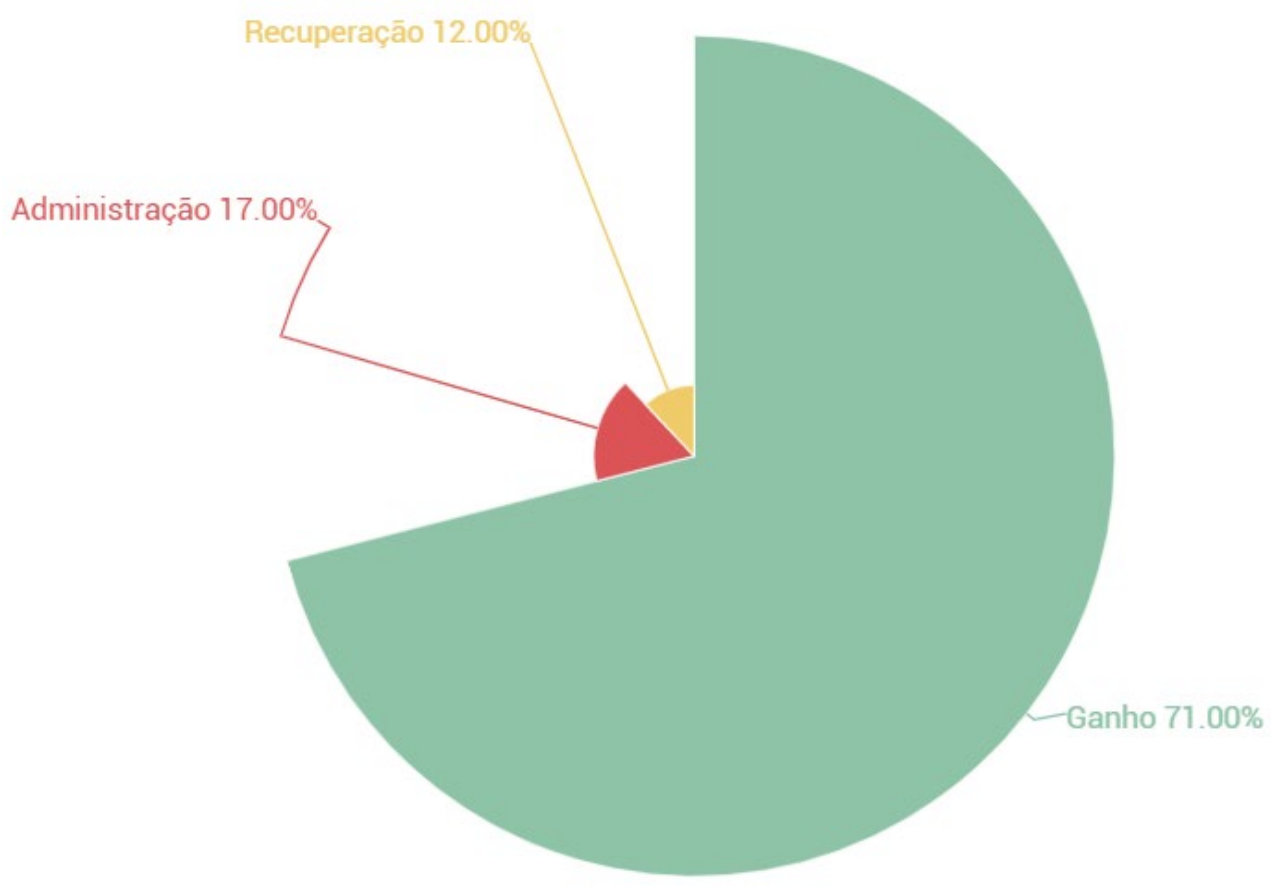

Fonte: Elaborado pelos autores para a finalidade do estudo

Em um vértice argumentativo, ao valer-se majoritariamente da função de enquadramento de atribuição de um julgamento moral sobre si própria, sublinhando o sucesso institucional adquirido com o suposto investimento contínuo em sustentabilidade e em ações sociais, bem como com o reconhecimento a partir de prêmios e certificações, a JBS S.A. procura, no plano da legitimidade pragmática, cooptar uma base de apoio por intermédio da (re)construção de sua reputação. Desenvolve tal estratégia por intermédio do recrutamento argumentativo de uma base de apoio amigável e no investimento majoritário em sua imagem, mais do que propriamente em seus produtos. Do ponto de vista da legitimidade moral, foco dos enquadramentos das notícias institucionais, a empresa procura oferecer demonstrações simbólicas de sucesso, sintonizadas com um ideário sustentável, vinculando-se a organizações consideradas legítimas. Nesse ponto, toca-se o escopo da legitimidade cognitiva, ao apresentar premiações e certificações que denotam respaldo externo.

Considerando os âmbitos dos comunicados aos investidores e as notícias institucionais, isso é, estratégias de comunicação que possuem públicos e objetivos distintos, constata-se que a JBS S.A. recorre nos anos de 2017 e de 2018 - embora por 
Marcos Paulo da Silva, Maryanna Beserra de Almeida, Marcia Maria dos Santos Bortolocci Espejo, lisabeth de Oliveira Vendramin \& Robert Armando Espejo

vias distintas - majoritariamente a recursos de legitimação devotados ao ganho e à recuperação de legitimidade - conforme explicita o gráfico da Figura 7:

Figura 7 - Estratégias retóricas de legitimação utilizadas pela JBS S.A. em comunicados aos investidores e notícias institucionais no período de 2017 e 2018

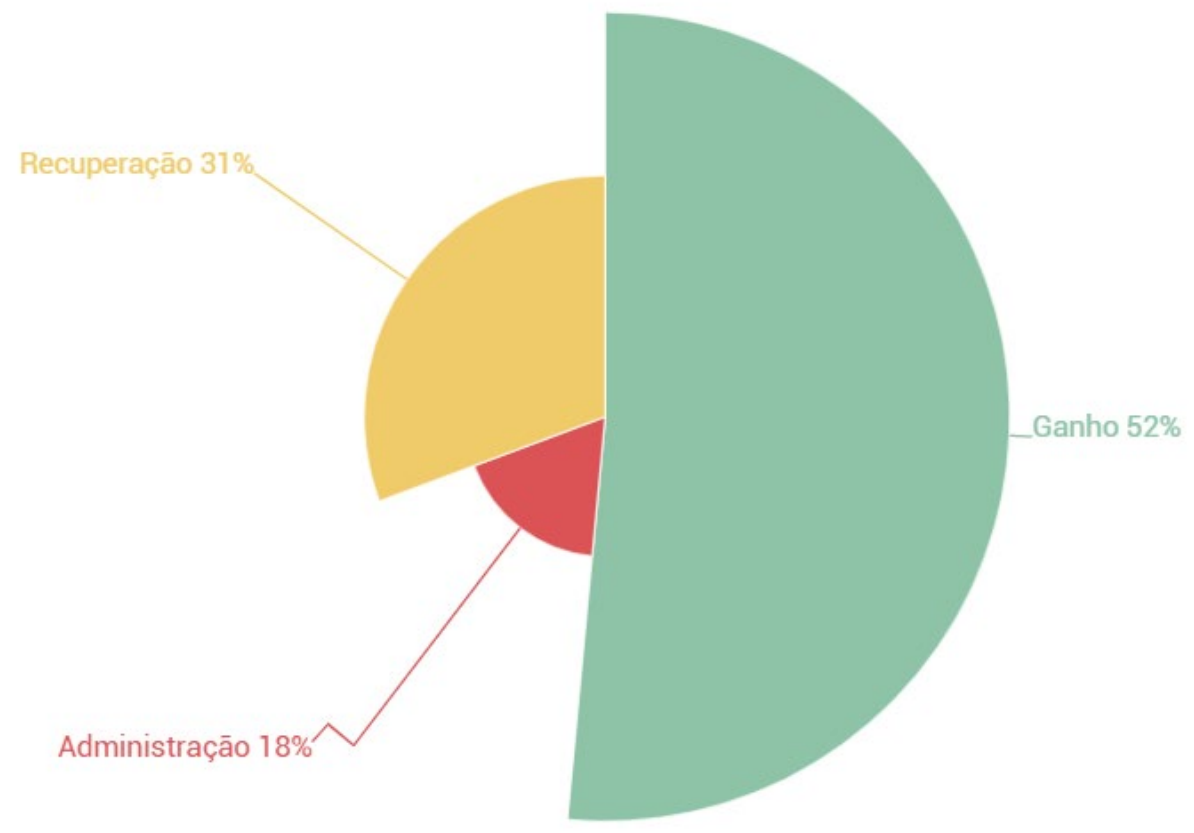

Fonte: Elaborado pelos autores para a finalidade do estudo

Foram verificadas 85 ocorrências de estratégias voltadas ao ganho - com destaque às notícias institucionais - e 51 ocorrências no plano da recuperação de legitimidade institucional - com ênfase nos comunicados aos investidores - em detrimento de apenas 29 ocorrências no campo da administração de legitimidade. Por fim, o diálogo metodológico com o terreno da framing analysis denota que as estratégias de ganho de legitimidade estão diretamente ligadas à função de enquadramento de atribuição de juízo moral (avaliação de agentes causais e seus efeitos a partir de crenças e valores sociais) ao passo em que as estratégias de recuperação de legitimidade vinculam-se à função de enquadramento da identificação de problemas (determinação do que está acontecendo, apontando benefícios ou custos, baseando-se em termos culturais comuns).

\section{Considerações finais}

Suchman (1995) defende que para a construção de sua legitimidade as organizações devem se portar de maneira proativa, sabendo antecipadamente seus 
objetivos, fraquezas e sua necessidade de legitimação. Todos os objetivos estratégicos de construção de legitimidade devem preceder a comunicação institucional propriamente dita. Nesse sentido, a tarefa de administrar a legitimidade é, de acordo com Suchman (1995), menos problemática em comparação às ações de ganho ou de recuperação, uma vez que, se uma instituição é tida como legítima, tal posição é supostamente aceita pela sociedade. Na maioria das vezes, para quebrar essa imagem é preciso haver uma ruptura brusca no contrato simbólico entre a organização e a sociedade, como no caso da empresa JBS S.A., envolvida em escândalos de corrupção que afetaram sua imagem como empresa íntegra e a percepção da qualidade de seus produtos.

O escopo da recuperação se assemelha ao do ganho de legitimidade. No entanto, a principal diferença é que a recuperação diz respeito a uma ação reativa a uma crise não prevista anteriormente. Em tese, é possível que a instituição recupere sua legitimidade se possuir o mínimo de credibilidade e de capacidade de se comunicar com seu público. Via de regra, a primeira ação da organização deslegitimada deve ser abordar a ruptura e, posteriormente, utilizar estratégias de recuperação de legitimidade, construindo, assim, uma imagem de antes e depois da quebra de aceitação (SUCHMAN, 1995).

Do ponto de vista metodológico, este estudo apresenta como alternativa analítica o diálogo entre os estudos de legitimidade institucional e a framing analysis para colocar em crivo as estratégias de comunicação corporativa. Os resultados da pesquisa mostramse relevantes. Verifica-se que o enquadramento noticioso contribui para a identificação de um maior impacto na utilização das estratégias retóricas de legitimação. Do total de 81 funções de enquadramento identificadas nos comunicados aos investidores e nas notícias institucionais da JBS S.A., 46 possuem como principal objetivo estabelecer um julgamento moral da própria empresa ou de terceiros, 29 apontam explicitamente um problema específico, assumindo um erro da instituição, ao passo em que apenas seis sugerem uma solução para o que foi exposto. Faz-se significativa a inferência de que a JBS S.A. não se vale em momento algum da função de enquadramento de construção de um diagnóstico de causas. De acordo com Entman (1993), os enquadramentos são responsáveis por enfatizar uma versão da realidade em detrimento de outra, utilizando-se da narrativa para auxiliar nesse processo. A ausência de um diagnóstico das causas da crise institucional, substituído pela mera identificação do problema seguido de julgamentos morais em sintonia com valores socialmente disseminados, demonstra - em um vértice das regras do mercado - uma estratégia comunicativa muito bem articulada pela empresa - embora levante sérios questionamentos do ponto de vista ético. 
A análise das nuvens de palavras também apresenta inferências pertinentes a respeito das escolhas feitas pela organização sobre o quê e como enunciar: nos comunicados aos investidores, por exemplo, em que foram elaboradas perguntas pelo grupo de acionistas e se tratavam diretamente das operações realizadas pela Polícia Federal, a JBS S.A. não responde em momento algum com referência aos nomes das operações ou estabelecendo qualquer outra referência direta; ao contrário, as respostas têm como objetivo demonstrar a preocupação da empresa, que afirma incentivar a ação policial, e negar o envolvimento, explicando as situações de forma a distanciar os escândalos de corrupção de sua imagem.

Não é segredo que a JBS S.A. enfrentou em 2017 e em 2018 momentos de crise severa. Foi o período no qual seus dirigentes diretos tornaram-se alvos de investigações da Polícia Federal e acabaram presos. Em 2017, ocorreram as operações Carne Fraca, Bullish, Greenfield e Cui Bono? e, em 2018, a empresa ainda enfrentou os desdobramentos de tais operações, como por exemplo a operação Capitu, desnovelamento da Lava Jato - que investigou a doação de dinheiro feita pela JBS S.A. a políticos do partido MDB, em troca de benefícios para exportação de produtos da empresa - e que acarretou na prisão, novamente, de seu ex-presidente, Joesley Batista (ZUBA, 2018). Além da operação Capitu, a JBS S.A. também foi investigada pela operação Porteira Aberta, deflagrada em 15 de junho de 2018 para apuração de fraudes na emissão de certificados sanitários em um frigorífico localizado em Barra do Garça, Mato Grosso (PF, 2018), e pela operação Vostok, deflagrada em 12 de setembro de 2018, responsável por investigar pagamento de propina ao governo de Mato Grosso do Sul em troca do não pagamento de mais de R\$ 200 milhões em impostos (NUCI, 2018).

Apesar do momento turbulento, a JBS S.A. apresentou recorde de exportação de produtos industrializados no primeiro trimestre de 2018, comercializando 16,8 mil toneladas para o mercado externo, com uma média de 5,6 mil toneladas ao mês. Esse valor é 33,3\% maior do que o mesmo período do ano anterior (JBS, 2018). O mercado externo, que logo após o escândalo da Carne Fraca impôs restrições à carne brasileira, voltou a comercializar com o Brasil. A JBS S.A. continuou exportando para mais de 150 países no mundo, com aproximadamente 350 mil consumidores (JBS, 2018). No final de 2017, o lucro líquido da empresa dobrou, passando de $\mathrm{R} \$ 233$,60 milhões, em 2016, para R \$ 534 milhões; além disso, ocorreu a redução da dívida líquida da empresa de R \$ 46,90 bilhões em 2016 para R \$ 45,20 bilhões em 2017. A variação da geração de caixa livre também foi positiva, teve um salto de R\$ 128 milhões, em 2016, para R $\$ 2.777$ bilhões 
em 2017 (JBS, 2018). Na pesquisa Top of Mind, a marca Friboi, da JBS S.A., ganhou por quatro anos consecutivos, inclusive em 2017 (TOP OF MIND, 2017), evidenciando que, apesar dos problemas enfrentados, a marca manteve-se como uma das preferidas pelo público.

Do ponto de vista empresarial, torna-se clara, com base nos dados levantados sobre a JBS S.A., a importância da escolha de enquadramentos argumentativos alinhados aos objetivos estratégicos de legitimidade institucional - muito embora, como mencionado, tais estratégicas possam resultar em dilemas e comprometimentos éticos no seio da sociedade. Trata-se de instrumentos poderosos para o ganho, a manutenção e a recuperação de legitimidade junto à sociedade - no caso da empresa em tela, verifica-se especialmente as estratégias de recuperação e de ganho. Finalmente, valendo-se das informações presentes na pesquisa, o que envolve suas opções metodológicas, faz-se possível refletir sobre como as estratégias retóricas de legitimação são capazes de transformar realidades nas organizações, uma vez que seu uso tem potencial de gestão empresarial e de gestão de riscos institucionais, mas nunca sem se desprender dos aspectos éticos, nesse caso, eclipsados pela JBS S.A. ao fechar-se à comunicação do diagnóstico das causas de sua grave crise.

\section{Referências}

AÇÕES da JBS caem mais de 10\% nesta sexta e as da BRF, mais de 7\%. G1, 17 de março de 2017. G1. Disponível em:

http://g1.globo.com/economia/mercados/noticia/bovespa-fecha-em-queda-com-fb-e-brfliderando-as-perdas.ghtml. Acesso em 28 jul. 2018.

BEUREN, Ilse Maria; GUBIANE, Clésia Ana; SOARES, Maurélio. Estratégias de legitimidade de Suchman evidenciadas nos relatórios de administração de empresas públicas no setor elétrico. Rev. Adm. Pública. Rio de Janeiro, v. 47, n. 4, jul/ago, 2009.

CONCEIÇÃO, S. H., DOURADO, G. B., BAQUEIRO, A. G., FREIRE, S., BRITO, P. C. Fatores determinantes no disclosure em Responsabilidade Social Corporativa (RSC): Um estudo qualitativo e quantitativo com empresas listadas na Bovespa. Gestão de Produção, v. 18, n. 3, 2011.

DIAS FILHO, J. M. A pesquisa qualitativa sob a perspectiva da Teoria da Legitimidade: uma alternativa para explicar e predizer políticas de evidenciação contábil. In: EnANPAD, 32., 2008. Anais [...]. Rio de Janeiro: ANPAD, 2008.

ENTMAN, R. M. Framing U.S. coverage of international news: Contrasts in narratives of the KAL and Iran air incidents. Journal of Communication, v. 41, n.4, p.16-27, 1991. 
ENTMAN, R. M. Framing: towards clarification of a fractured paradigm. Journal Communication, v. 43, n.4, 1993.

FERNANDES, Karina; ZANELLI, José Carlos. O processo de construção e reconstrução das identidades dos indivíduos nas organizações. RAC, v. 10, n. 1, Jan./Mar. 2006.

GITLIN, T. The whole world is watching: mass media in the making and unmaking of the New Left. Berkeley, Los Angeles e Londres: UniversityofCalifornia Press, 2003.

GOFFMAN, E. Os quadros da experiência social: uma perspectiva de análise.

Petrópolis: Ed. Vozes. 2012.

JBS. Relatório anual de sustentabilidade 2015. Disponível em:

https://ri.jbs.com.br/informacoes-financeiras/relatorios-anuais/. Acesso em 21 set. 2018.

JBS. Relatório anual de sustentabilidade 2017. Disponível em:

https://ri.jbs.com.br/informacoes-financeiras/relatorios-anuais/. Acesso em 21 set. 2018.

JBS. Relatório anual de sustentabilidade 2018. Disponível em:

https://ri.jbs.com.br/informacoes-financeiras/relatorios-anuais/. Acesso em 30 jul. 2019.

JBS tem resultado melhor que o esperado no $3^{\circ}$ trimestre. Folha de S. Paulo, 14 de novembro de 2018. Disponível em:

https://www1.folha.uol.com.br/mercado/2018/11/jbs-tem-resultado-melhor-que-oesperado-no-3o-trimestre.shtml. Acesso em 20 nov. 2018.

J\&F. Alimentos, 2017. Disponível em http://jfinvest.com.br/negocios/alimentos/. Acesso em: 21 set. 2017.

KUYPERS, J. A. Rhetorical Criticism: Perspectives in Action. Lanham, MD: Lexington Books. 2009.

LAMBERTI, Lucio; LETTIER, Emanuele. Gaining legitimacy in converging industries: Evidence from the emerging market of functional food. European Management Journal 29, 462- 475, 2011.

LINDBLOM, Cristi K. The implications of organizational legitimacy for corporate social performance and disclosure. In: CRITICAL PERSPECTIVES ON ACCOUNTING, 1994. Paper [...], Nova York, 1994.

MAFEI, Maristela; CECATO, Valdete. Comunicação corporativa. São Paulo: Contexto, 2011.

NUCI, Renan. Cúpula do Governo é alvo de operação da PF por propina da JBS.

Correio do Estado, 12 de setembro de 2018. Disponível em: https://www.correiodoestado.com.br/cidades/cupula-do-governo-e-investigada-poroperar-esquema-de-propina-com-a/336296/. Acesso em 20 nov.2018. 
PETTIGREW, Andrew M. Strategy formulation as a political process. International studies of management \& organization, v. 7, n. 2, p. 78-87, 1977.

PF e MPF deflagram operação contra esquema de corrupção na JBS em MT. G1, 15 de junho de 2018. Disponível em: https://g1.globo.com/mt/mato-grosso/noticia/pf-e-mpfdeflagram-operacao-contra-esquema-de-corrupcao-na-jbs-em-mt.ghtml. Acesso em: 20 nov. 2018.

\section{POLÍCIA FEDERAL. Operação Bullish investiga fraudes em empréstimos no}

BNDES. Disponível em: http://www.pf.gov.br/agencia/noticias/2017/05/operacaobullish-investiga-fraudes-em-emprestimos-no-bndes. Acesso em: 21 set. 2017.

SUCHMAN, M. Managing legitimacy: strategic and institutional approaches. Academy of Management Review. 1995.

TOP OF MIND. Friboi conquista o Top of Mind, 2018. Disponível em: http://topofmindbrasilia.com.br/friboi-conquista-o-top-of-mind/. Acesso em: 20 nov. 2018.

ZUBA, Fernando. PF prende vice-governador de MG, Joesley Batista e Ricardo Saud em investigação sobre suposto esquema na Agricultura. G1, 09 de novembro de 2018. Disponível em: https://g1.globo.com/mg/minas-gerais/noticia/2018/11/09/policiafederal-cumpre-mandados-em-desdobramento-da-operacao-lava-jato.ghtml. Acesso em: 20 nov. 2018.

\footnotetext{
${ }^{a}$ Doutor em Comunicação Social pela Universidade Metodista de São Paulo (UMESP), com estágio de doutorado-sanduíche na Syracuse University (Nova Iorque, Estados Unidos). Professor dos Programas de Pós-Graduação em Comunicação (Mestrado) e Estudos de Linguagens (Doutorado) da Universidade Federal de Mato Grosso do Sul (UFMS).

${ }^{\mathrm{b}}$ Graduada em Arquivologia pela Universidade de Brasília (UNB). Mestre em Administração pela Universidade Federal de Mato Grosso do Sul (UFMS).

${ }^{\mathrm{c}}$ Doutora em Controladoria e Contabilidade pela Universidade de São Paulo (USP). Docente dos Programas de Pós-graduação em Ciências Contábeis (Mestrado) e Administração (Mestrado e Doutorado) da Universidade Federal de Mato Grosso do Sul (UFMS).

${ }^{\mathrm{d}}$ Doutora em Controladoria e Contabilidade pela Universidade de São Paulo (USP). Docente do Programa de Pós-Graduação em Ciências Contábeis da Universidade Federal de Mato Grosso do Sul (UFMS).

${ }^{\mathrm{e}}$ Mestre em Contabilidade pela Universidade Federal do Paraná (UFPR) e Doutorando em Ciências Ambientais e Sustentabilidade Agropecuária pela Universidade Católica Dom Bosco (UCDB). Docente da Escola de Administração e Negócios da Universidade Federal do Mato Grosso do Sul (UFMS).
} 